\title{
Case Report \\ Rapidly Growing Thyroid Mass in an Immunocompromised Young Male Adult
}

\author{
Mónica Santiago, ${ }^{1}$ José Hernán Martinez, ${ }^{1}$ Coromoto Palermo, ${ }^{1}$ \\ Carlos Figueroa, ${ }^{1}$ Oberto Torres, ${ }^{1}$ Rafael Trinidad, ${ }^{1}$ Eva Gonzalez, ${ }^{1}$ \\ Maria de Lourdes Miranda, ${ }^{1}$ Miosotis Garcia, ${ }^{2}$ and Guillermo Villamarzo ${ }^{2}$ \\ ${ }^{1}$ Department of Endocrinology, Metabolism, and Diabetes, San Juan City Hospital, Puerto Rico \\ ${ }^{2}$ Department of Surgical Pathology and Cytopathology, Hato Rey Pathology Associates Inc., Puerto Rico \\ Correspondence should be addressed to Mónica Santiago; sjmedcoor@gmail.com
}

Received 8 March 2013; Accepted 19 May 2013

Academic Editors: O. Isozaki, M. P. Kane, and L. Meyer

Copyright (C) 2013 Mónica Santiago et al. This is an open access article distributed under the Creative Commons Attribution License, which permits unrestricted use, distribution, and reproduction in any medium, provided the original work is properly cited.

\begin{abstract}
We describe a 20-year-old man diagnosed with a myelodysplastic syndrome (MDS), admitted to our hospital due to pancytopenia and fever of undetermined origin after myelosuppression with chemotherapy. Disseminated aspergillosis (DIA) was suspected when he developed skin and lung involvement. A rapidly growing mass was detected on the left neck area, during hospitalization. A thyroid ultrasound reported a $3.7 \times 2.5 \times 2.9 \mathrm{~cm}$ oval heterogeneous structure, suggestive of an abscess versus a hematoma. Fine needle aspiration of the thyroid revealed invasion of aspergillosis. Fungal thyroiditis is a rare occurrence. Thyroid fungal infection is difficult to diagnose; for this reason it is rarely diagnosed antemortem. To our knowledge, this is the 10th case reported in the literature in an adult where the diagnosis of fungal invasion to the thyroid was able to be corroborated antemortem by fine needle aspiration biopsy.
\end{abstract}

\section{Introduction}

Thyroiditis by fungal organisms is infrequent. Most cases have been reported on immunocompromised patients, such as those with organ transplant, leukemias, receiving certain types of chemotherapy, subjects with human immunodeficiency virus, and others types of immunosuppression. This uncommon site of infections could be explained by the unique features of the thyroid gland [1], that includes protective mechanisms, such as rich blood supply, separation of the neck by fascial planes, high iodine content, and a fibrous capsule [2]. Among the different types of fungal thyroiditis, Aspergillus spp. are the predominant causative fungus for thyroiditis and asymptomatic thyroid infiltration [2-4]. Aspergillus thyroiditis (AT) has primarily been a postmortem diagnosis on immunocompromised patients with diagnosed disseminated invasive Aspergillosis (DIA) $[5,6]$. Reports of antemortem diagnosis are rare, and for this reason in the literature it is difficult to find reports of surviving patients. Here, we report a case describing AT, in an immunocompromised young adult male with a rapidly growing thyroid mass; diagnosis was able to be performed antemortem by FNA cytology. We also review the epidemiology, clinical manifestations, diagnosis, and outcome of the different AT cases reported in the medical literature published during the years 1980-2012 through a search of the PubMed database.

\section{Case}

A 20-year-old man was admitted to our hospital on July 2012. He was diagnosed as having an MDS one month before; by that moment he had received two courses of chemotherapy consisting of azacitidine. Admission to the hospital was due to pancytopenia and fever of undetermined origin.

During hospitalization, initial chest X-ray revealed a right perihilar rounded confluent pulmonary opacity, and a subsequent noncontrast-enhanced tomography confirmed the infiltrating nodular lesion measuring $2.5 \times 2.3 \times 1.9 \mathrm{~cm}$. 


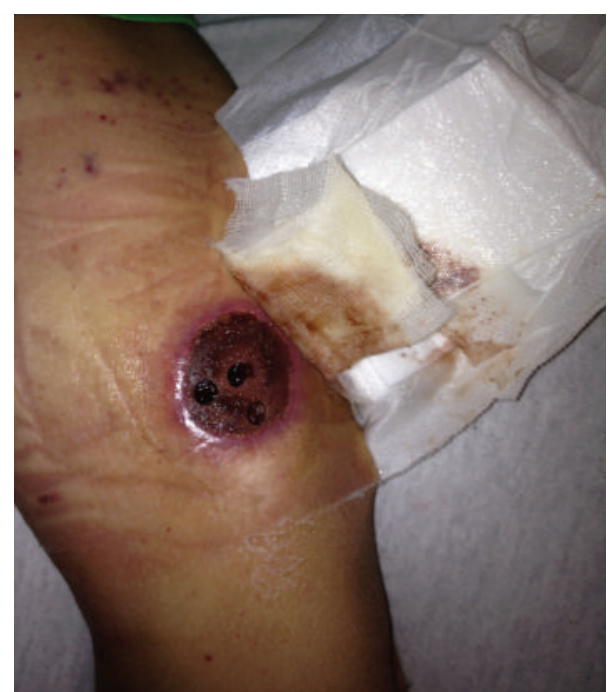

FIGURE 1: Cutaneous aspergillosis.

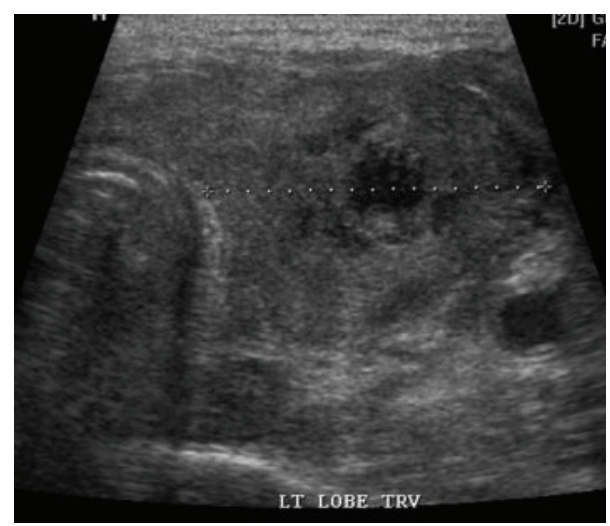

FIgURE 2: Thyroid sonogram showing a $3.7 \times 2.5 \times 2.9 \mathrm{~cm}$ oval heterogeneous structure, in the left lobe.

With these findings and the skin lesions (Figure 1), DIA was suspected. Intravenous liposomal amphotericin B $(5 \mathrm{mg} / \mathrm{Kg}$ daily) was initiated. One week after hospitalization, a rapidly painless growing mass was detected on the left neck area by the patient. Physical examination revealed a diffusely enlarged nontender palpable mass in the left thyroid lobe. Laboratory data showed normal thyroid function tests (Table 1). A thyroid ultrasound (Figure 2 ) revealed a $3.7 \times 2.5 \times$ $2.9 \mathrm{~cm}$ oval heterogeneous structure, suggestive of an abscess versus a hematoma.

Microscopy of the thyroid, after fine needle aspiration, revealed infectious thyroiditis with suppurative inflammation and abundant debris. Septate fungal hyphae with branching at acute angles were identified (Figure 3 ). These findings were consistent with a fungal thyroiditis caused by Aspergillus spp. A culture of the aspirated fluid showed no growth. At this moment the patient was switched from previous antifungal to voriconazole ( $4 \mathrm{mg} / \mathrm{Kg}$ IV q $12 \mathrm{hr}$ ).

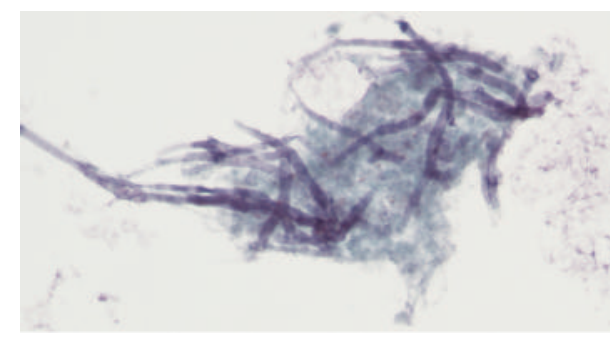

FIGURE 3: The histological appearance of Aspergillus hyphae with septae, branching at $45^{\circ}$ (silver methenamine, $\times 1000$ ).

TABLE 1: Results of the patient's laboratory tests.

\begin{tabular}{lcc}
\hline Test & Result & Normal Range (unit) \\
\hline White blood cell count & 2,000 & $5,000-10,000\left(/ \mathrm{mm}^{3}\right)$ \\
Neutrophils & 21 & $55-75(\%)$ \\
Lymphocytes & 70 & $20-44(\%)$ \\
Monocytes & 11.6 & $2-8(\%)$ \\
Haemoglobin & 6.4 & $12-16(\mathrm{~g} / \mathrm{dL})$ \\
Haematocrit & 18.9 & $37.0-47.0(\%)$ \\
Patelet count & 17,000 & $150,000-450,000\left(/ \mathrm{mm}^{3}\right)$ \\
C-reactive protein & 374.9 & $0.1-5.0(\mathrm{mg} / \mathrm{L})$ \\
Total thyroxine $(\mathrm{T} 4)$ & 6.36 & $4.5-12.0(\mu \mathrm{g} / \mathrm{dL})$ \\
Thyroid stimulating & & \\
$\quad$ & \\
hormone $(\mathrm{TSH})$ & 1.07 & $0.3-4.0(\mathrm{mIU} / \mathrm{L})$ \\
\hline
\end{tabular}

Two weeks after the initiation of voriconazole, he developed wheezing and dyspnea. His respiratory function deteriorated rapidly, needing an endotracheal intubation, and he was further transferred to the intensive care unit, where he finally died.

\section{Discussion}

Fungal pathogens are increasingly encountered on immunocompromised patients. Fungal thyroiditis is a rare occurrence. In the last decade, more than 500 cases of different infectious thyroiditis have been reported, but few cases were fungal, most likely due to the unique features of the thyroid gland, that includes protective mechanisms, such as rich blood supply, separation of the neck by fascial planes, high iodine content, and a fibrous capsule [2]. Although several fungi may infect the thyroid gland $[2,4,14-18]$, thyroid fungal infection occurs rarely and is clinically overt in a minority of patients.

In a review of 41 fungal thyroiditis cases published between 1970 and 2005, Goldani et al. [19] found that Aspergillus species (spp.) were the most commonly reported cause of fungal thyroid infection. Candida spp. were the second most common cause; other fungal etiologies reported include Cryptococcus neoformans, Coccidioides immitis, Histoplasma capsulatum, and Pseudallescheria boy$d i i$, while $P$. jiroveci is the most common cause of fungal thyroiditis in patients with AIDS, reflecting the high incidence of pneumocystosis in these patients [20]. This observation could 
TABLE 2: Review of the medical literature describing cases of the Aspergillus thyroiditis diagnosed antermortem by fine needle aspiration (FNA) cytology in patient over 18 years old.

\begin{tabular}{|c|c|c|c|c|c|c|}
\hline Reference & Year & $\begin{array}{c}\text { Age } \\
\text { (years/sex) }\end{array}$ & Comorbidity & Thyroid function & $\begin{array}{c}\text { Treatment of } \\
\text { thyroid dysfunction }\end{array}$ & Outcome \\
\hline $\begin{array}{l}\text { Solary et al. } \\
\text { [7] }\end{array}$ & 1987 & $43 / \mathrm{F}$ & Renal transplant recipient & Euthyroid & Not reported & Deceased \\
\hline $\begin{array}{l}\text { Torres et al. } \\
\text { [8] }\end{array}$ & 1999 & $24 / \mathrm{F}$ & $\begin{array}{l}\text { Systemic erythematous } \\
\text { disease, end stage renal } \\
\text { disease }\end{array}$ & Hyperthyroid & Not reported & Deceased \\
\hline $\begin{array}{l}\text { Ayala et al. } \\
\text { [9] }\end{array}$ & 2001 & $31 / \mathrm{F}$ & $\begin{array}{l}\text { Acquired } \\
\text { immunodeficiency } \\
\text { syndrome }\end{array}$ & Hyperthyroid & Atenolol & Deceased \\
\hline Jang et al. [10] & 2004 & $49 / \mathrm{F}$ & $\begin{array}{l}\text { Acute lymphoblastic } \\
\text { leukemia }\end{array}$ & Hyperthyroid & Not reported & Survived \\
\hline Sion et al. [4] & 2004 & $46 / \mathrm{M}$ & Renal transplant recipient & $\begin{array}{c}\text { Euthyroid } \\
(\downarrow \text { TSH })\end{array}$ & Not reported & Deceased \\
\hline Sion et al. [4] & 2004 & $49 / ?$ & Renal transplant recipient & Not reported & Hemithyroidectomy & Deceased \\
\hline Elzi et al. [11] & 2005 & $62 / \mathrm{M}$ & Liver transplant recipient & Not reported & Total thyroidectomy & Deceased \\
\hline $\begin{array}{l}\text { Matsui et al. } \\
{[12]}\end{array}$ & 2006 & $56 / \mathrm{M}$ & Renal transplant recipient & Not reported & Not reported & Survived \\
\hline $\begin{array}{l}\text { Guetgemann } \\
\text { et al. [13] }\end{array}$ & 2006 & $30 / \mathrm{F}$ & Renal transplant recipient & Hyperthyroid & NSAIDS beta blockers & Survived \\
\hline $\begin{array}{l}\text { Santiago et al. } \\
\text { Current } \\
\text { Publication }\end{array}$ & 2013 & $20 / \mathrm{M}$ & Myelodysplastic syndrome & Euthyroid & Not required & Deceased \\
\hline
\end{tabular}

suggest that Aspergillus spp. have an increased propensity relative to other fungus to infiltrate the thyroid gland or that Aspergillus spp. are more likely to cause enough destruction of thyroid tissue to cause symptomatic disease.

We performed a review of the literature of the cases reported with Aspergillus thyroiditis in patients over 18 years of age in the medical literature published during 1980-2012 through a search of the PubMed database [4, 7-13, 21-34]. Here, we only report those cases where the diagnosis was able to be corroborated antemortem by fine needle aspiration (FNA) cytology (Table 2).

The infection by Aspergillus spp. is difficult to diagnose; since more than $50 \%$ of patients do not exhibit clinical or laboratory manifestations of thyroid dysfunction [5]. Thyroid involvement by Aspergillus was found at autopsy as part of disseminated aspergillosis in $11(46 \%)$ of 24 patients without clinical manifestations and laboratory evidence of thyroid dysfunction. Nineteen (79\%) of the 24 patients with AT died, most likely due to the underlying immunosuppression associated with disseminated fungal infection and the delay in diagnosis and treatment. Although involvement of the thyroid gland has been detected at autopsy in patients with disseminated fungal disease, there are few reports that have detected the infection by fine needle aspiration (FNA) cytology antemortem (Table 2). To our knowledge, this is the 10th case reported where FNA biopsy plays a major role in diagnosing this entity.

Finally, Aspergillus thyroiditis is difficult to diagnose without biopsy, but should be considered in the differential diagnosis of any thyroid nodule, mass, or abscess, particularly in patients with conditions causing immunodeficiency. Besides, the survival of patients with invasive aspergillosis depends on the early diagnosis and prompt initiation of therapeutic measures. In conclusion, we report a case describing Aspergillus thyroiditis, in a immunocompromised young adult male with a rapidly growing thyroid mass; diagnosis was able to be performed antemortem by FNA cytology.

\section{References}

[1] R. Tozzoli, O. Barzilai, M. Ram et al., "Infections and autoimmune thyroid diseases: parallel detection of antibodies against pathogens with proteomic technology," Autoimmunity Reviews, vol. 8, no. 2, pp. 112-115, 2008.

[2] S. A. Berger, J. Zonszein, P. Villamena, and N. Mittman, "Infectious diseases of the thyroid gland," Reviews of Infectious Diseases, vol. 5, no. 1, pp. 108-122, 1983.

[3] M. S. Lionakis, G. Samonis, and D. P. Kontoyiannis, "Endocrine and metabolic manifestations of invasive fungal infections and systemic antifungal treatment," Mayo Clinic Proceedings, vol. 83, no. 9, pp. 1046-1060, 2008.

[4] M. L. Sion, M. C. Armenaka, I. Georgiadis, G. Paraskevopoulos, and I. Nikolaidis, "Aspergillus fumigatus abscesses of the thyroid with obstruction of the esophagus," Thyroid, vol. 14, no. 9, pp. 786-788, 2004.

[5] J. Nguyen, R. Manera, and C. Minutti, "Aspergillus thyroiditis: a review of the literature to highlight clinical challenges," European Journal of Clinical Microbiology and Infectious Diseases, vol. 31, no. 12, pp. 3259-3264, 2012. 
[6] M. Vogeser, A. Haas, D. Aust, and G. Ruckdeschel, "Postmortem analysis of invasive aspergillosis in a tertiary care hospital," European Journal of Clinical Microbiology and Infectious Diseases, vol. 16, no. 1, pp. 1-6, 1997.

[7] E. Solary, G. Rifle, J. M. Chalopin et al., "Disseminated aspergillosis revealed by thyroiditis in a renal allograft recipient," Transplantation, vol. 44, no. 6, pp. 839-840, 1987.

[8] A. M. Torres, S. Agrawal, S. Peters et al., "Invasive aspergillosis diagnosed by fine-needle aspiration of the thyroid gland," Thyroid, vol. 9, no. 11, pp. 1119-1122, 1999.

[9] A. R. Ayala, S. Basaria, K. E. Roberts, and D. S. Cooper, "Aspergillus thyroiditis," Postgraduate Medical Journal, vol. 77, no. 907 , article 336, 2001.

[10] K. S. Jang, X. H. Han, Y. Oh, and S. P. Seung, "Aspergillosis of the thyroid gland diagnosed by fine needle aspiration cytology," Acta Cytologica, vol. 48, no. 6, pp. 875-876, 2004.

[11] L. Elzi, G. Laifer, J. Bremerich, J. Vosbeck, and M. Mayr, "Invasive apergillosis with myocardial involvement after kidney transplantation," Nephrology Dialysis Transplantation, vol. 20, no. 3, pp. 631-634, 2005.

[12] Y. Matsui, Y. Sugawara, K. Tsukada, Y. Kishi, J. Shibahara, and M. Makuuchi, "Aspergillus thyroiditis in a living donor liver transplant recipient," Journal of Infection, vol. 53, no. 6, pp. e231e233, 2006.

[13] A. Guetgemann, V. M. Brandenburg, M. Ketteler, J. Riehl, and J. Floege, "Unclear fever 7 weeks after renal transplantation in a 56-year-old patient," Nephrology Dialysis Transplantation, vol. 21, no. 8, pp. 2325-2327, 2006.

[14] R. T. Gandhi, S. R. Tollin, and E. W. Seely, "Diagnosis of Candida thyroiditis by fine needle aspiration," Journal of Infection, vol. 28, no. 1, pp. 77-81, 1994.

[15] A. M. Avram, C. A. Sturm, C. W. Michael, J. C. Sisson, and C. A. Jaffe, "Cryptococcal thyroiditis and hyperthyroidism," Thyroid, vol. 14, no. 6, pp. 471-474, 2004.

[16] L. Z. Goldani, C. Klock, A. Diehl, A. C. Monteiro, and A. L. Maia, "Histoplasmosis of the thyroid," Journal of Clinical Microbiology, vol. 38, no. 10, pp. 3890-3891, 2000.

[17] A. Babu, E. Lacuesta, and S. Patel, "Cervical blastomycosis masquerading as a thyroid mass. This is the first reported case of extrapulmonary blastomycosis manifesting as a thyroid mass," Endocrine Practice, vol. 11, no. 1, pp. 65-68, 2005.

[18] J. D. Smilack and R. Argueta, "Coccidioidal infection of the thyroid," Archives of Internal Medicine, vol. 158, no. 1, pp. 89-92, 1998.

[19] L. Z. Goldani, A. P. Zavascki, and A. L. Maia, "Fungal thyroiditis: an overview," Mycopathologia, vol. 161, no. 3, pp. 129-139, 2006.

[20] D. C. Aron, "Endocrine complications of the acquired immunodeficiency syndrome," Archives of Internal Medicine, vol. 149, no. 2, pp. 330-333, 1989.

[21] Y. Solak, H. Atalay, A. Nar et al., "Aspergillus thyroiditis in a renal transplant recipient mimicking subacute thyroiditis," Transplant Infectious Disease, vol. 13, no. 2, pp. 178-181, 2011.

[22] H. Erdem, A. K. Uzunlar, U. Yildirim, M. Yildirim, and M. F. Geyik, "Diffuse infiltration of Aspergillus hyphae in the thyroid gland with multinodular goiter," Indian Journal of Pathology and Microbiology, vol. 54, pp. 814-816, 2011.

[23] H. W. Murray, J. O. Moore, and R. D. Luff, "Disseminated aspergillosis in a renal transplant patient: diagnostic difficulties re emphasized," Johns Hopkins Medical Journal, vol. 137, no. 5, pp. 235-237, 1975.
[24] Y. Kishi, M. Negishi, M. Kami et al., "Fatal airway obstruction caused by invasive aspergillosis of the thyroid gland," Leukemia and Lymphoma, vol. 43, no. 3, pp. 669-671, 2002.

[25] M. W. Hornef, J. Schopohl, C. Zietz et al., "Thyrotoxicosis induced by thyroid involvement of disseminated Aspergillus fumigatus infection," Journal of Clinical Microbiology, vol. 38, no. 2, pp. 886-887, 2000.

[26] W. M. Keane, W. P. Potsic, and L. J. Perloff, "Aspergillus thyroiditis," Otolaryngology, vol. 86, no. 5, pp. 761-765, 1978.

[27] C. Sergi, J. Weitz, W. J. Hofmann et al., "Aspergillus endocarditis, myocarditis and pericarditis complicating necrotizing fasciitis. Case report and subject review," Virchows Archiv, vol. 429, no. 2-3, pp. 177-180, 1996.

[28] G. G. Winzelberg, J. Gore, D. Yu, and A. G. Vagenakis, "Aspergillus flavus as a cause of thyroiditis in an immunosuppressed host," Johns Hopkins Medical Journal, vol. 144, no. 3, pp. 90-93, 1979.

[29] P. C. Iwen, M. E. Rupp, M. R. Bishop et al., "Disseminated aspergillosis caused by Aspergillus ustus in a patient following allogeneic peripheral stem cell transplantation," Journal of Clinical Microbiology, vol. 36, no. 12, pp. 3713-3717, 1998.

[30] P. H. Kalina and R. J. Campbell, "Aspergillus terreus endophthalmitis in a patient with chronic lymphocytic leukemia," Archives of Ophthalmology, vol. 109, pp. 102-103, 1991.

[31] T. Mori, M. Matsumura, K. Yamada et al., "Systemic aspergillosis caused by an aflatoxin-producing strain of Aspergillus flavus," Journal of Medical and Veterinary Mycology, vol. 36, no. 2, pp. 107-112, 1998.

[32] H. Narimatsu, Y. Morishita, A. Kohno et al., "Systemic infection of Aspergillus flavus in a patient with acute lymphoblastic leukemia," Rinsho Ketsueki, vol. 44, pp. 1026-1031, 2003.

[33] J. F. Fraumeni Jr. and R. E. Fear, "Purulent pericarditis in aspergillosis," Annals of internal medicine, vol. 57, pp. 823-828, 1962.

[34] G. W. Allan and D. H. Andersen, "Generalized aspergillosis in an infant 18 days of age," Pediatrics, vol. 26, pp. 432-440, 1960. 


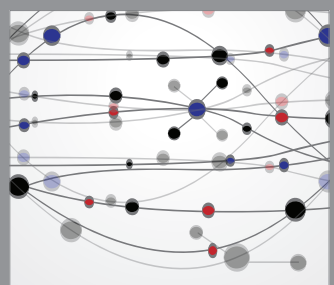

The Scientific World Journal
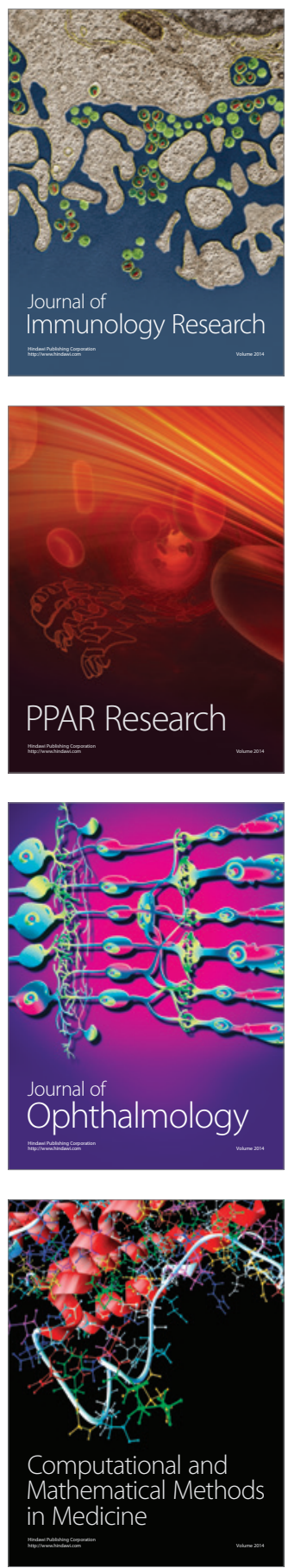

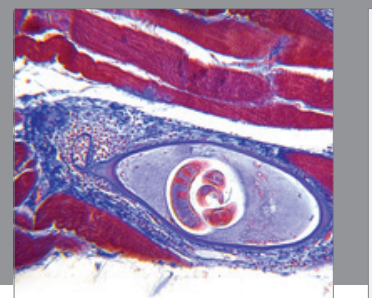

Gastroenterology

Research and Practice
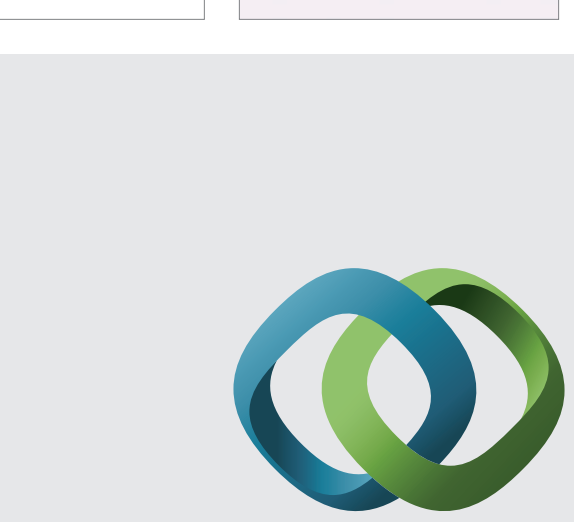

\section{Hindawi}

Submit your manuscripts at

http://www.hindawi.com
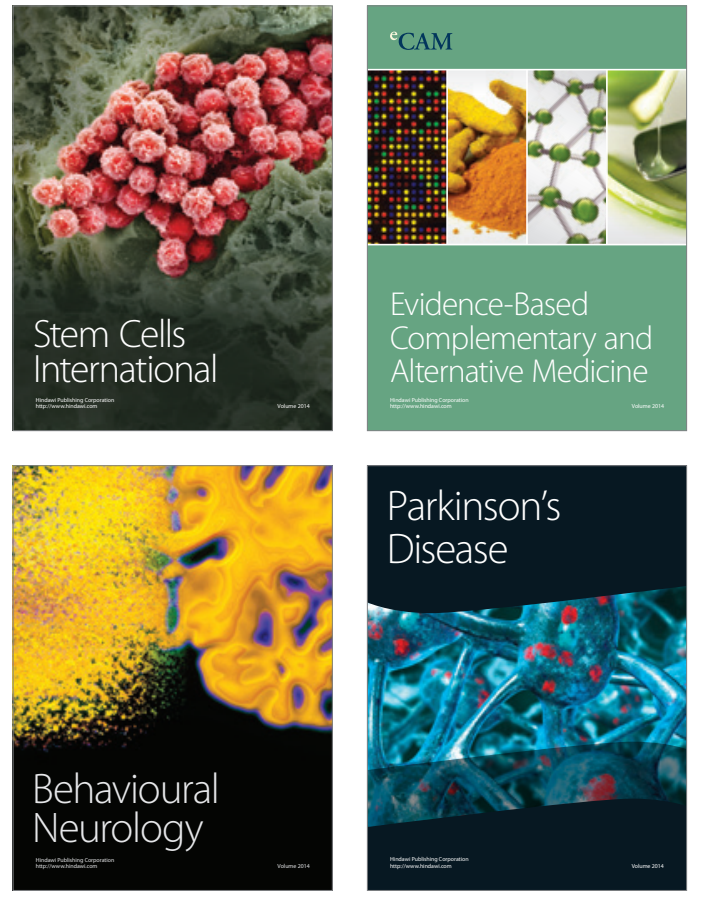
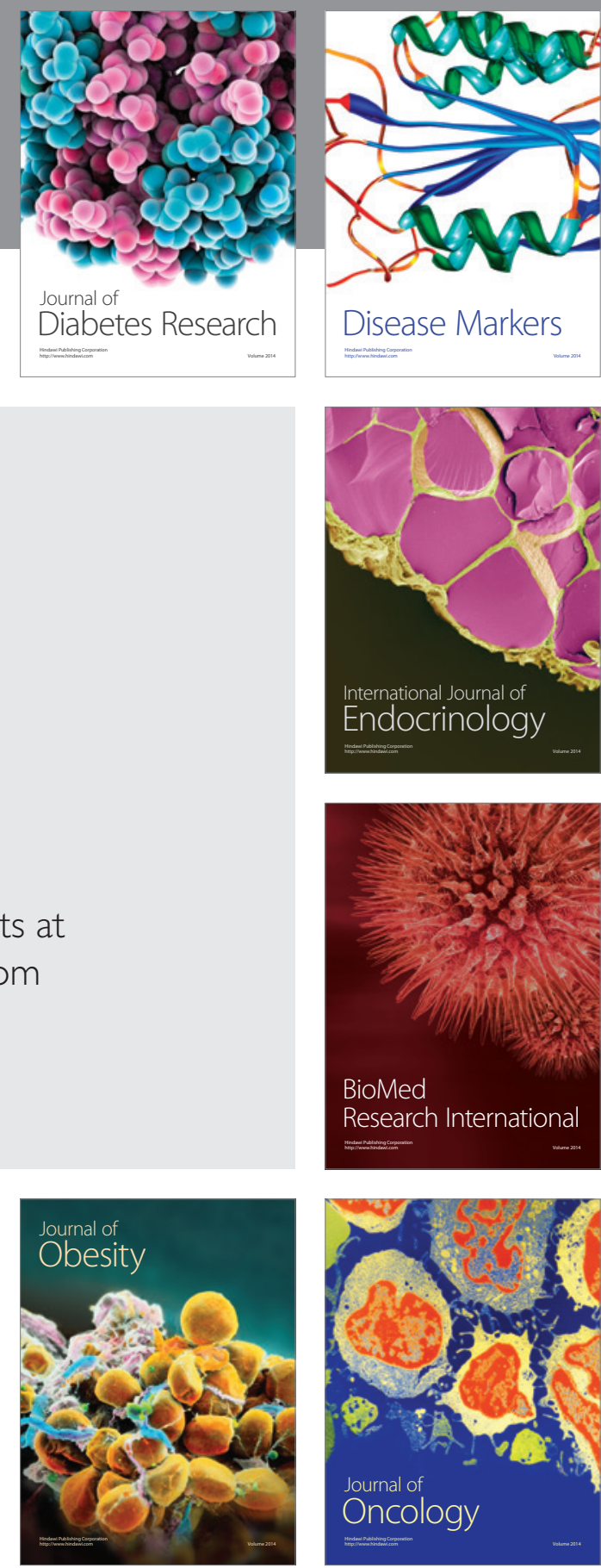

Disease Markers
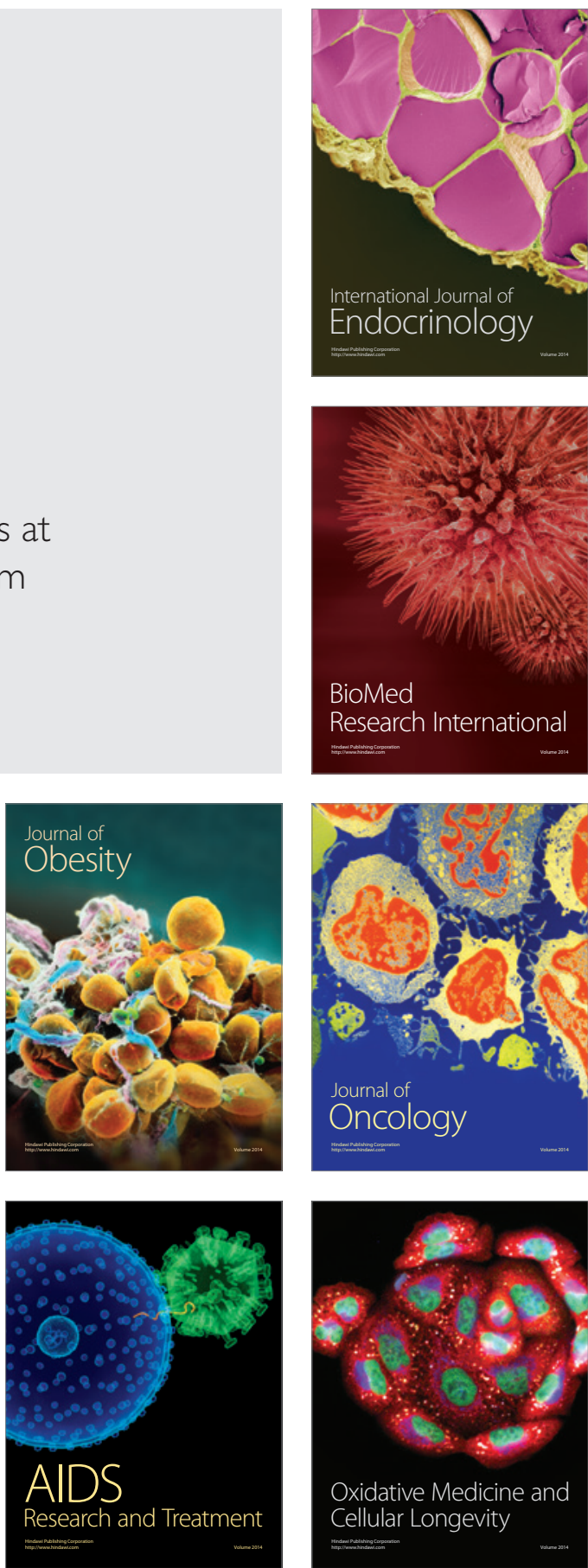